\title{
The Geometry of the Catalytic Active Site in [FeFe]-hydrogenases is Determined by Hydrogen Bonding and Proton Transfer
}

JIFU DUAN, Stefan Mebs, Moritz Senger, Konstantin Laun, Florian Wittkamp, Joachim Heberle, Thomas Happe, Eckhard Hofmann, Ulf-Peter Apfel, Martin Winkler, Michael Haumann, and Sven T. Stripp

ACS Catal., Just Accepted Manuscript • DOI: 10.1021/acscatal.9b02203 • Publication Date (Web): 29 Aug 2019

Downloaded from pubs.acs.org on September 6, 2019

\section{Just Accepted}

"Just Accepted" manuscripts have been peer-reviewed and accepted for publication. They are posted online prior to technical editing, formatting for publication and author proofing. The American Chemical Society provides "Just Accepted" as a service to the research community to expedite the dissemination of scientific material as soon as possible after acceptance. "Just Accepted" manuscripts appear in full in PDF format accompanied by an HTML abstract. "Just Accepted" manuscripts have been fully peer reviewed, but should not be considered the official version of record. They are citable by the Digital Object Identifier (DOI®). "Just Accepted" is an optional service offered to authors. Therefore, the "Just Accepted" Web site may not include all articles that will be published in the journal. After a manuscript is technically edited and formatted, it will be removed from the "Just Accepted" Web site and published as an ASAP article. Note that technical editing may introduce minor changes to the manuscript text and/or graphics which could affect content, and all legal disclaimers and ethical guidelines that apply to the journal pertain. ACS cannot be held responsible for errors or consequences arising from the use of information contained in these "Just Accepted" manuscripts. 


\section{The Geometry of the Catalytic Active Site in [FeFe]-hydrogenases is Determined by Hydrogen Bonding and Proton Transfer}

Jifu Duan ${ }^{1}$, Stefan Mebs², Moritz Senger ${ }^{3}$, Konstantin Laun ${ }^{3}$, Florian Wittkamp ${ }^{4}$, Joachim Heberle $^{3}$, Thomas Happe ${ }^{1}$, Eckhard Hofmann ${ }^{5}$, Ulf-Peter Apfel ${ }^{4,6}$, Martin Winkler ${ }^{1}$, Michael Haumann ${ }^{2}$, and Sven T. Stripp ${ }^{3 *}$

${ }^{1}$ Faculty of Biology and Biotechnology, Photobiotechnology, Ruhr-University Bochum, 44801 Bochum, Germany

${ }^{2}$ Department of Physics, Biophysics of Metalloenzymes, Freie Universität Berlin, 14195 Berlin, Germany

${ }^{3}$ Department of Physics, Experimental Molecular Biophysics, Freie Universität Berlin, 14195 Berlin, Germany

${ }^{4}$ Faculty of Chemistry and Biochemistry, Inorganic Chemistry I, Ruhr University Bochum, 44801 Bochum, Germany

${ }^{5}$ Faculty of Biology and Biotechnology, Protein Crystallography, Ruhr University Bochum, 44801 Bochum, Germany

${ }^{6}$ Fraunhofer UMSICHT, 46047 Oberhausen, Germany

*Correspondence to:

Sven T. Stripp, Freie Universität Berlin, Fachbereich Physik, Arnimallee 14, 14195 Berlin, Germany, Phone: +49 30838 55069, Email: sven.stripp@,fu-berlin.de 


\begin{abstract}
$[\mathrm{FeFe}]$-hydrogenases are efficient metalloenzymes that catalyze the oxidation and evolution of molecular hydrogen, $\mathrm{H}_{2}$. They serve as a blueprint for the design of synthetic $\mathrm{H}_{2}$-forming catalysts. [FeFe]-hydrogenases harbor a six-iron cofactor that comprises a [4Fe-4S] cluster and a unique diiron site with cyanide, carbonyl, and hydride ligands. To address the ligand dynamics in catalytic turnover and upon carbon monoxide (CO) inhibition, we replaced the native aminodithiolate group of the diiron site by synthetic dithiolates, inserted into wild-type and amino acid variants of the [FeFe]-hydrogenase HYDA1 from Chlamydomonas reinhardtii. The reactivity with $\mathrm{H}_{2}$ and $\mathrm{CO}$ was characterized using in situ and transient infrared spectroscopy, protein crystallography, quantum chemical calculations, and kinetic simulations. All cofactor variants adopted characteristic populations of reduced species in the presence of $\mathrm{H}_{2}$ and showed significant changes in $\mathrm{CO}$ inhibition and reactivation kinetics. Differences were attributed to varying interactions between polar ligands and the dithiolate head group and/or the environment of the cofactor (i.e., amino acid residues and water molecules). The presented results show how catalytically relevant intermediates are stabilized by inner-sphere hydrogen bonding suggesting that the role of the aminodithiolate group must not be restricted to proton transfer. These concepts may inspire the design of improved enzymes and biomimetic $\mathrm{H}_{2}$-forming catalysts.
\end{abstract}

Keywords: metalloenzymes, cofactor dynamics, infrared spectroscopy, protein crystallography, quantum chemistry 


\section{INTRODUCTION}

Hydrogenases are metalloenzymes that catalyze the reversible reduction of protons to molecular hydrogen $\left(\mathrm{H}_{2}\right) .{ }^{1}$ They have been found in all domains of life participating in cellular energy metabolism and hydrogen sensing. Three different classes were identified: [FeFe]hydrogenases catalyze both proton reduction and $\mathrm{H}_{2}$ oxidation, e.g. in bacteria and algae, while $[\mathrm{NiFe}]-$ and $[\mathrm{Fe}]$-hydrogenases are predominantly $\mathrm{H}_{2}$-oxidizing enzymes in bacteria and archaea. Hydrogenase activity is reversibly inhibited by carbon monoxide (CO) usually impaired by molecular oxygen $\left(\mathrm{O}_{2}\right) \cdot{ }^{2-5}$ Here, the reactivity of [ $\left.\mathrm{FeFe}\right]$-hydrogenases with $\mathrm{CO}$ and/or $\mathrm{H}_{2}$ was employed to unravel molecular interactions involved in structural dynamics and catalytic performance at the active site.

The active site cofactor of [FeFe]-hydrogenases (H-cluster) comprises a unique diiron site covalently linked to a [4Fe-4S] cluster via a single cysteine (Fig. 1) ${ }^{6-8}$ The proximal and distal iron ions of the diiron site $\left(\mathrm{Fe}_{\mathrm{p}}, \mathrm{Fe}_{\mathrm{d}}\right)$ carry a single $\mathrm{CO}$ and cyanide $\left(\mathrm{CN}^{-}\right)$ligand each and share a bridging carbonyl $(\mu \mathrm{CO})$ in the oxidized resting state, Hox. ${ }^{5,9}$ An open apical coordination site at $\mathrm{Fe}_{\mathrm{d}}$ characterizes the so-called "rotated geometry" of the H-cluster. ${ }^{10} \mathrm{~A}$ chain of water molecules connects protein surface and $[4 \mathrm{Fe}-4 \mathrm{~S}]$ cluster while conserved amino acids and a small water cluster have been shown to form a dedicated proton transfer trajectory to the diiron site. ${ }^{11}$ The protein-cofactor interface is formed by an adjacent cysteine residue and the unique aminodithiolate group (ADT) of the H-cluster (Fig. 1). ${ }^{12}$ Any variation of the cysteine or nitrogen head group severely diminishes $\mathrm{H}_{2}$ turnover, which revealed the essential role of the ADT group as a proton transfer relay. ${ }^{13-15}$ 

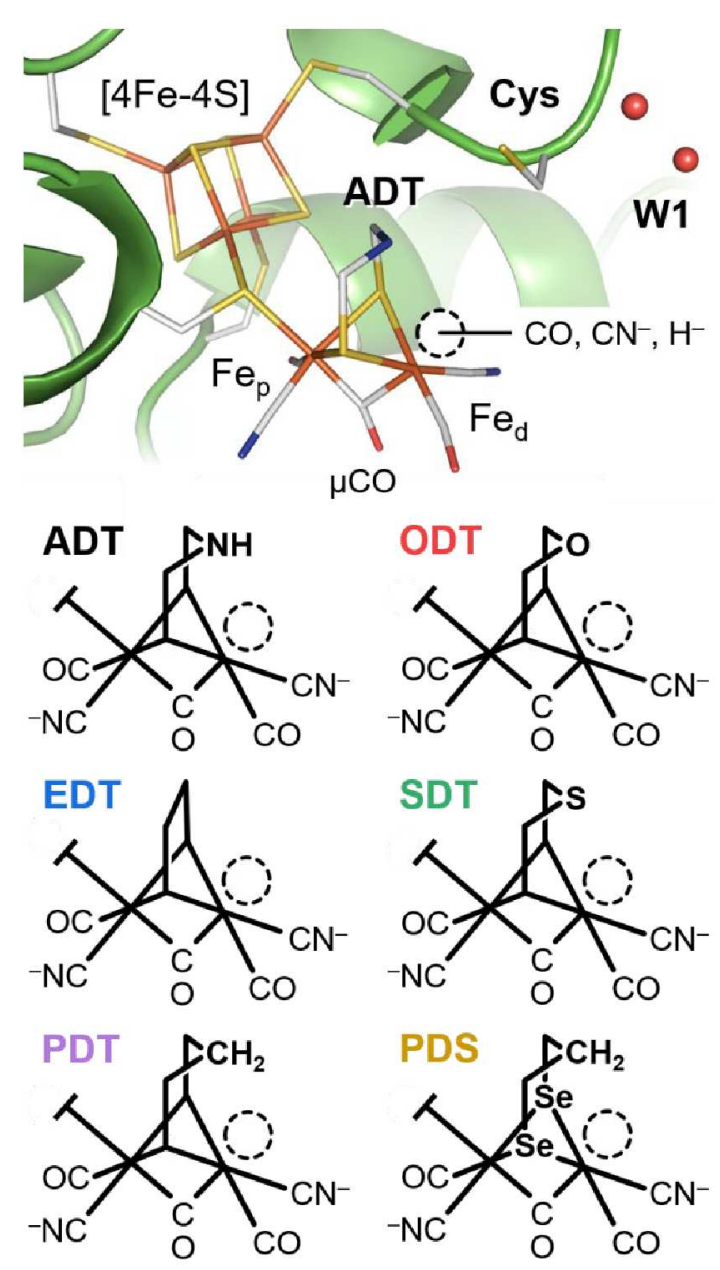

Figure 1. Active site and catalytic cofactor of [FeFe]-hydrogenase. The upper panel shows the active-ready, oxidized $\mathrm{H}$-cluster and the immediate protein environment (pdb entry 4XDC). The catalytic proton transfer pathway includes the aminodithiolate group (ADT), a cysteine (C169 in HYDA1) and a water cluster (W1). The open coordination site (dashed circle) may accommodate $\mathrm{CO}, \mathrm{CN}^{-}$, or $\mathrm{H}^{-}$ligands. Below, the six analyzed cofactor variants are shown in a simplified representation. Cofactor variant EDT was crystallized here for the first time (pdb entry $6 \mathrm{H} 63)$.

Various redox states of the H-cluster have been identified (Table 1). For example, protoncoupled electron transfer to the $[4 \mathrm{Fe}-4 \mathrm{~S}]$ cluster preserves the rotated, Hox-like geometry in the one-electron reduced state Hred' ${ }^{16-18}$ Vibrational coupling of ligands in the CO-inhibited 
states Hox-CO and Hred'-CO suggests an additional, equatorial CO ligand and an apical cyanide ligand $\left(a \mathrm{CN}^{-}\right)$at $\mathrm{Fe}_{\mathrm{d}}{ }^{19}$ although earlier crystal structures were modeled with an apical carbonyl $(a \mathrm{CO}) .^{20,21}$ Based on isotope editing studies we proposed $a \mathrm{CO}$ ligation at the reduced diiron site of Hred and Hsred together with a bridging hydride $\left(\mu \mathrm{H}^{-}\right) .{ }^{22}$ Other authors favor an open coordination site at $\mathrm{Fe}_{\mathrm{d}}$ and a $\mu \mathrm{CO}$ or "semi-bridging" carbonyl ligand in these states. ${ }^{23-}$ ${ }^{26}$ In the two-electron reduced catalytic intermediate $\mathbf{H h y d}$, an apical hydride species at $\mathrm{Fe}_{\mathrm{d}}$ was verified. ${ }^{27-29}$ The remarkable flexibility of the diiron site is broadly accepted; however, the molecular proceedings of hydrogen turnover are under debate. ${ }^{30}$ How variations in $\mathrm{H}$-cluster geometry are related to hydrogen bonding changes and proton transfer is in the focus of the present investigation.

Table 1. Electronic and structural features of H-cluster species.

\begin{tabular}{|c|c|c|c|c|c|c|}
\hline $\begin{array}{c}\text { redox } \\
\text { species }\end{array}$ & $\begin{array}{c}{[4 \mathrm{Fe}-4 \mathrm{~S}]} \\
\text { cluster }\end{array}$ & $\begin{array}{c}\text { diiron } \\
\text { site }^{\dagger}\end{array}$ & $\begin{array}{l}\text { bridging } \\
\text { species }\end{array}$ & $\begin{array}{c}\text { apical } \\
\text { species }^{\#}\end{array}$ & $\begin{array}{l}\text { alternative } \\
\text { annotation }\end{array}$ & reference \\
\hline Hox & +2 & I / II & $\mathrm{CO}$ & none & none & 5,9 \\
\hline Hox-CO & +2 & I / II & $\mathrm{CO}$ & $\mathrm{CN}^{-}$ & none & 19 \\
\hline Hred' & +1 & I / II & $\mathrm{CO}$ & none & Hred & $16-18$ \\
\hline Hred'-CO & +1 & I / II & $\mathrm{CO}$ & $\mathrm{CN}^{-}$ & Hred-CO & 13 \\
\hline Hhyd & +1 & II / II & $\mathrm{CO}$ & $\mathrm{H}^{-}$ & none & $27-29$ \\
\hline Hred & +2 & II / II & $\mathrm{H}^{-}$ & $\mathrm{CO}$ & HredH $^{+}$ & 22 \\
\hline Hsred & +1 & II / II & $\mathrm{H}^{-}$ & $\mathrm{CO}$ & HsredH $^{+}$ & 22 \\
\hline
\end{tabular}

$\dagger$ Formal redox levels are given for $\mathrm{Fe}_{\mathrm{p}} / \mathrm{Fe}_{\mathrm{d}}$. \$ Alternative bridging and apical ligands were proposed for Hred and Hsred. ${ }^{24-26}$ \# The crystal structures of CO-inhibited CPI was modeled with an apical CO ligand. ${ }^{20}$

In vitro maturation of [FeFe]-hydrogenases generated $\mathrm{H}$-cluster variants that contain artificial dithiolate ligands (Fig. 1) affecting the geometry of the $\mathrm{Fe}_{\mathrm{d}}$ site, the reactivity with small molecules, and the hydrogen bonding network at the active site. ${ }^{31-33}$ Such cofactor variants show characteristic infrared signatures, accumulate different $\mathrm{H}$-cluster states in the presence of 
$\mathrm{H}_{2}$, and exhibit distinct $\mathrm{CO}$ sensitivities. ${ }^{13-15}$ These observations prompted us to investigate the underlying substrate affinities and cofactor geometries. Nine variants of the [FeFe]hydrogenase from Chlamydomonas reinhardtii (HYDA1) were compared, including different dithiolate head groups as well as replacements of an adjacent cysteine (C169 in HYDA1) by side-directed mutagenesis. We employed qualitative and quantitative infrared spectroscopy to analyze the reactions with $\mathrm{H}_{2}$ and/or $\mathrm{CO}$ as well as X-ray crystallography, quantum chemical calculations, and kinetic simulations to characterize the structure and function of the variants. Inhibition with $\mathrm{CO}$ proved to be a valuable tool for probing the active site properties independent of catalytic activity and functional proton transfer. The drastic variations observed in the stabilization of Hhyd and Hox-CO are attributed to proton transfer and hydrogenbonding interactions in the inner and outer coordination sphere ${ }^{34}$ of the H-cluster. Such effects were found to determine the geometry of the active site cofactor under catalytic and inhibitory conditions.

\section{RESULTS AND DISCUSSION}

[FeFe]-hydrogenase apo-protein from C. reinhardtii (HYDA1) was heterologously expressed and synthesized in E. coli. After purification, protein was activated with synthetic diiron complexes as described previously. ${ }^{32}$ The resulting enzymes were analyzed by in situ attenuated total reflection Fourier-transform infrared spectroscopy (ATR FTIR) with regard to reactions with $\mathrm{H}_{2}$ and $\mathrm{CO}$. The study included native enzyme (ADT) as well as cofactor variants ODT, EDT, and SDT as well as PDT and PDS (Table 2). Furthermore, we addressed protein/ cofactor interactions by comparison of native enzyme with amino acid variant C169A and its cofactor "double" variants ODT and EDT (Table 2). Solving the crystal structure of the EDT variant of [FeFe]-hydrogenase CPI from Clostridium pasteurianum verified the lack of a central atom in 
the dithiolate bridgehead as well as the absence of a putative water molecule in the respective position. (PDB entry 6H63, Fig. S1).

Table 2. Cofactor and amino acid variants analyzed in this study.

\begin{tabular}{ccccc}
\hline annotation & $\begin{array}{c}\text { full } \\
\text { name }\end{array}$ & $\begin{array}{c}\text { head } \\
\text { group }\end{array}$ & $\begin{array}{c}\text { position } \\
169\end{array}$ & $\begin{array}{c}\text { additional } \\
\text { references }\end{array}$ \\
\hline ADT & amino-dt & $\mathrm{NH}$ & $-\mathrm{CH}_{2}-\mathrm{SH}$ & 8,12 \\
ODT & oxo-dt & $\mathrm{O}$ & $-\mathrm{CH}_{2}-\mathrm{SH}$ & 8,14 \\
EDT & ethane-dt & none & $-\mathrm{CH}_{2}-\mathrm{SH}$ & 18 \\
SDT & sulfur-dt & $\mathrm{S}$ & $-\mathrm{CH}_{2}-\mathrm{SH}$ & 8,14 \\
PDT & propane-dt & $\mathrm{CH}_{2}$ & $-\mathrm{CH}_{2}-\mathrm{SH}$ & 8,13 \\
PDS & propane-ds & $\mathrm{CH}_{2}$ & $-\mathrm{CH}_{2}-\mathrm{SH}$ & 33 \\
ADT-C169A & amino-dt & $\mathrm{NH}^{-}$ & $-\mathrm{CH}_{3}$ & none \\
ODT-C169A & oxo-dt & $\mathrm{O}$ & $-\mathrm{CH}_{3}$ & none \\
EDT-C169A & ethane-dt & none & $-\mathrm{CH}_{3}$ & none \\
\hline
\end{tabular}

$\dagger$ "dt" and "ds" refers to dithiolate and diselenide, respectively

\$ HYDA1 numbering (equivalent 299 in CPI)

Spectral Characterization. The HYDA1 cofactor variants in as-isolated form adopted varying mixtures of oxidized, reduced, and CO-inhibited H-cluster species as visible in the FTIR spectra. A unique identification of the vibrational bands of the $\mathrm{CO}$ and $\mathrm{CN}^{-}$ligands in the oxidized states (Hox, Hox-CO) and oxidized-protonated states (HoxH, HoxH-CO), as well as in the corresponding one-electron reduced states (Hred', Hred'-CO) was accomplished (Fig. S2, Tables S1 and S2). This is of key importance since Hox, HoxH, and Hred' give rise to similar IR signatures and produce different CO-inhibited species. ${ }^{17-19}$ We note that a consistent set of IR spectra of these states for all cofactor variants was so far not available.

Despite catalytic activities typically $<1 \%$ relative to native HYDA $1,{ }^{13,14}$ near-quantitative enrichment of $\mathrm{Hox}$ was achieved at $\mathrm{pH} \geq 8$ upon prolonged exposure to $\mathrm{N}_{2}$ gas (auto-oxidation, 
see Fig. S3). In comparison to ADT, the IR bands of Hox for HYDA1 EDT, SDT, and PDT variants showed only small $\mathrm{CO} / \mathrm{CN}^{-}$band frequency up-shifts while ODT exhibited slightly larger up-shifts and bands of PDS are shifted to lower frequencies (Fig. 2A and Fig. S4). Quantum chemical calculations at QM/MM and DFT levels accurately reproduced the $\mathrm{CO} / \mathrm{CN}^{-}$ stretching frequencies of Hox for all variants (Fig. S5). These results provide strong evidence that the overall electronic configuration of the oxidized H-cluster is similar in all variants. The frequency shifts are explained by small variations in electron density distribution, i.e. due to increased electronegativity of the ODT and SDT head groups ${ }^{14}$ or an overall increase of electron density in the PDS variant..$^{33}$
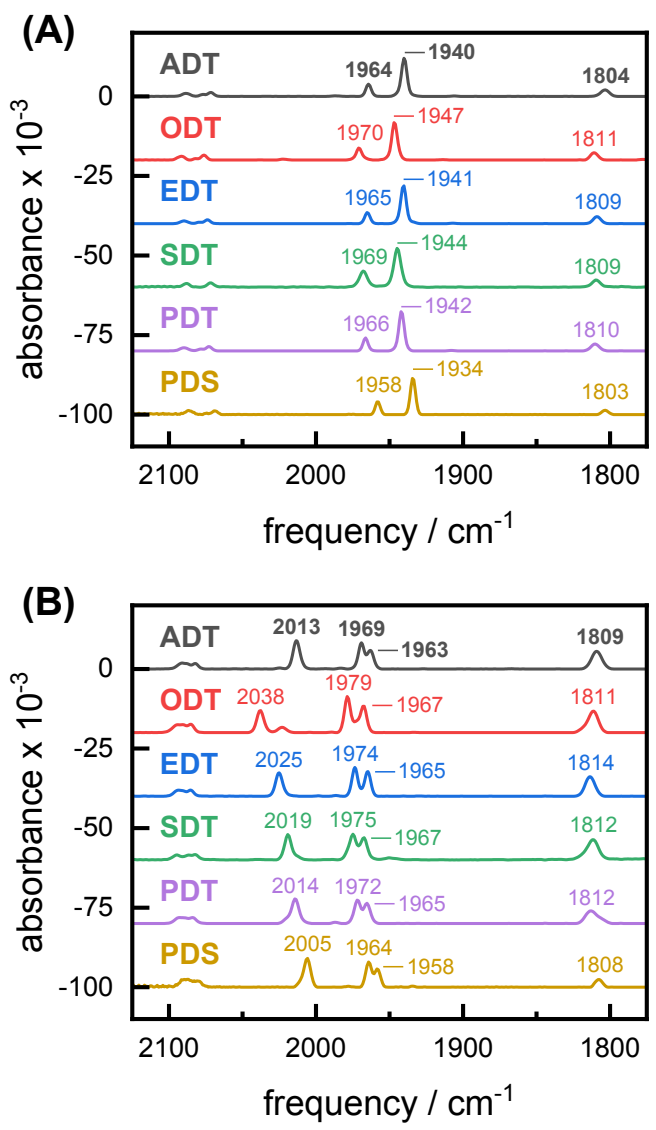

Figure 2. Infrared spectra of HYDA1 cofactor variants. (A) Normalized spectra of Hox in the presence of $\mathrm{N}_{2}(\mathrm{pH}$ ). (B) Normalized spectra of Hox-CO in the presence of $\mathrm{CO}(\mathrm{pH} 8)$. See Tables $\mathrm{S} 1$ and $\mathrm{S} 2$ for $\mathrm{CN}^{-}$band frequencies. 
Exposure of oxidized HYDA1 to CO gas stabilized the CO-inhibited state (Fig. 2B). While the overall IR signature of Hox-CO was conserved in all cofactor variants, ODT and EDT showed pronounced up-shifts, in particular of the highest-frequency CO band $\left(25 \mathrm{~cm}^{-1}\right.$ or $12 \mathrm{~cm}^{-1}$, respectively). It is important to note that this band results from a coupled vibrational mode involving all $\mathrm{CO}$ ligands and must not be assigned to exogenous $\mathrm{CO} .{ }^{19}$ The mean differences in $\mathrm{CN}^{-}$stretching frequencies for Hox-CO ODT and EDT are the same as in Hox (Fig. S4).

Quantum chemistry was employed to evaluate conceivable diiron site geometries for Hox-CO (Fig. S5 and S6). Best agreement between experimental and calculated IR frequencies was found for a structure with an apical $\mathrm{CN}^{-}$ligand compared to a geometry with an apical $\mathrm{CO}$ ligand at $\mathrm{Fe}_{\mathrm{d}}$, as reported earlier. ${ }^{19}$ The IR signatures indicate a comparable electronic configuration of the Hox-CO cofactor in all variants, in accordance with the data for Hox. However, the calculations did not fully reproduce the CO frequency up-shifts as observed for ODT and EDT. This suggests an influence on the electronic configuration of the H-cluster beyond inner coordination sphere effects that could not be included in the calculations. We assume that altered interactions between the H-cluster and its protein environment ${ }^{35-37}$ may cause the diverging IR signatures of Hox-CO in cofactor variants ODT and EDT, which remain unspecified in the absence of respective crystal structures. In the next step, we explored the influence of the dithiolate group on $\mathrm{CO}$ inhibition in kinetic experiments.

Inhibition and Reactivation Kinetics with CO. In situ ATR FTIR spectroscopy facilitated a quantitative comparison of $\mathrm{CO}$ inhibition and reactivation kinetics for all HYDA1 cofactor variants (Fig. 3). Already at 1\% CO partial pressure, ADT, ODT, EDT, and PDS rapidly and completely converted from Hox $\rightarrow$ Hox-CO, which indicates similar and high CO binding affinities. In contrast, SDT and PDT adopted only approximately $65 \%$ or $20 \%$ Hox-CO after 
$250 \mathrm{~s}$ under $1 \% \mathrm{CO}\left(\mathrm{t}_{1}\right.$ in Fig. 3) and converted to Hox-CO at $100 \%$ CO partial pressure only incompletely ( $\sim 90 \%$ or $\sim 70 \%$, respectively). This behavior implied diminished CO binding affinities. Notably, the CO sensitivity of the selenium-substituted PDS variant was similar to ADT, which suggests that changes in charge density distribution and/or conformational flexibility contributes to the apparent CO affinity. ${ }^{15}$ Under the chosen conditions, the kinetics of $\mathrm{CO}$ inhibition and reactivation were found to be reproducible with an experimental variance not exceeding 5\% (Fig. S7, Tab. S4). To investigate CO binding free from macroscopic effects (i.e. gas diffusion) we exploited transient IR spectroscopy in a flash-photolysis approach similar to what was reported by Mirmohades and coworkers. ${ }^{38,39}$ Following CO photolysis induced by a $450 \mathrm{~nm}$ laser pulse, equally rapid CO re-binding $\left(\mathrm{t}_{1 / 2}=1.3 \pm 0.2 \mathrm{~ms}\right)$ was observed for ADT, ODT, and EDT (Fig. S8). Accordingly, the microscopic velocity of CO binding is independent of the dithiolate head group.

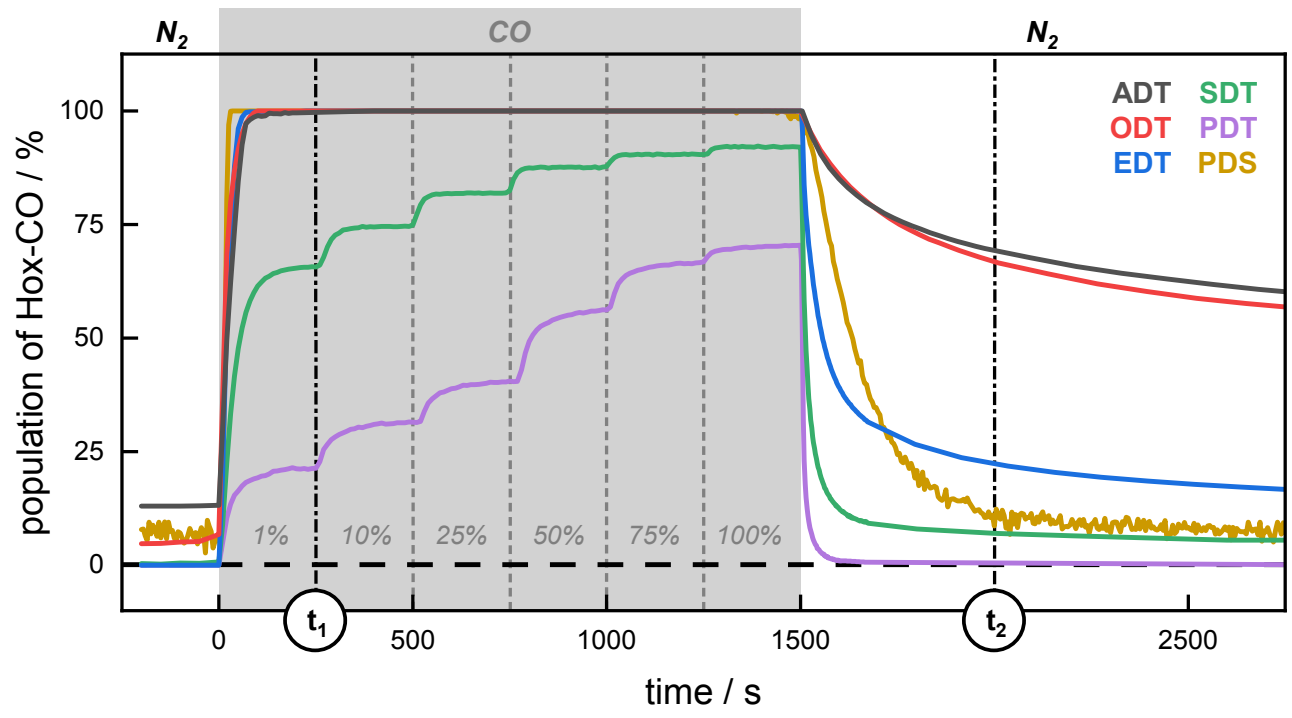

Figure 3. CO inhibition and reactivation kinetics. Relative population of Hox-CO (\%) as a function of time and CO concentration in the gas phase $(0-100 \%) \cdot \mathrm{t}_{1}$ : [Hox-CO] after $250 \mathrm{~s}$ at $1 \% \mathrm{CO}$ in $99 \% \mathrm{~N}_{2} . \mathrm{t}_{2}:[\mathrm{Hox}-\mathrm{CO}$ ] at $500 \mathrm{~s}$ after removal of $\mathrm{CO}$ from the gas stream. ADT, ODT, EDT, and PDS exhibit very similar inhibition kinetics $\left(\mathrm{t}_{1 / 2}<10 \mathrm{~s}\right.$ for $1 \% \mathrm{CO}$ and full 
inhibition after $\sim 60 \mathrm{~s}$ ). The low $\mathrm{CO}$ affinity of SDT and PDT is mirrored in the fast reactivation kinetics; ADT and ODT showed very slow reactivation, accordingly. Despite being easily inhibited by CO, EDT and PDS exhibited relatively fast reactivation.

The varying degrees of $\mathrm{CO}$ inhibition were mostly mirrored by the Hox-CO $\rightarrow$ Hox reactivation kinetics in the absence of $\mathrm{CO}$ gas $(\mathrm{t}>1500 \mathrm{~s}$ in Fig. 3). While rapid and almost complete Hox-CO decay was observed for SDT and PDT, a slower and incomplete reactivation within the experimental data acquisition period was observed for EDT and PDS. ADT and ODT showed similar but very slow and least complete Hox-CO decay. The altered CO inhibition and reactivation kinetics in some of the dithiolate variants suggests that the macroscopic $\mathrm{CO}$ affinity is defined by variations of the relative $\mathrm{CO}$ binding and release rates and an altered ligand rearrangement, possibly. As a prerequisite for $\mathrm{CO}$ binding, earlier studies from our groups ${ }^{19}$ have suggested an alternative to the crystalized Hox geometry, which is characterized by a partial rotation of the equatorial $\mathrm{CN}^{-}$ligand at $\mathrm{Fe}_{\mathrm{d}}$. In this structure, the distance between $\mathrm{CN}^{-}$and ADT-NH is diminished by $\sim 1.3 \AA$ reflecting a weak inner-sphere hydrogen bond in "Hox ${ }_{\mathrm{b}}$ " that may compensate for the proposed outer-sphere hydrogen bond to a lysine residue in the crystallographic conformation of "Hox ${ }_{\mathrm{a}}$ " (Fig. 4A). ${ }^{35}$ A similar structural equilibrium of Hox has been discussed in the context of $\mathrm{O}_{2}$ induced deactivation by Fourmond and coworkers. ${ }^{40}$ To gain further insight into the observed inhibition and reactivation profiles, we employed numerical simulations including a two-step reaction model with a reversible geometry change (conformational isomers "Hox ${ }_{\mathrm{a}}$ " and "Hox ${ }_{\mathrm{b}}$ "), followed by CO binding to "Hox ${ }_{\mathrm{b}}$ " and formation of Hox-CO (Eq. S3, Fig. S9). Variation of the relative rate constants qualitatively reproduced the experimentally observed Hox-CO equilibrium populations and rate constants of the dithiolate variants (Fig. 4B). 

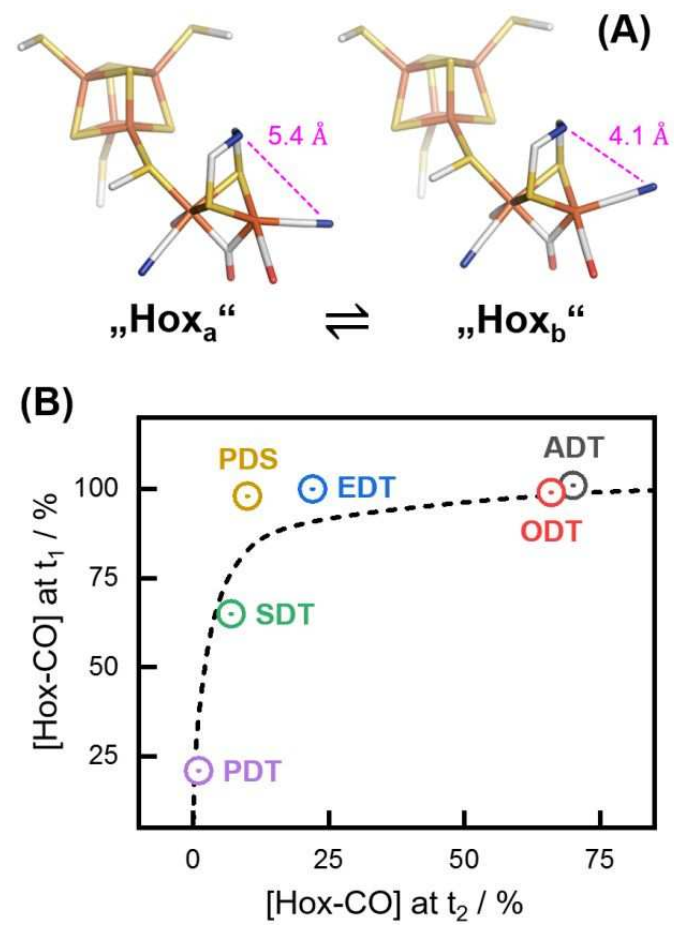

Figure 4. Conceivable isomers of Hox and simulation of relative Hox-CO populations. (A)

Out of two structural isomers of the active-ready oxidized state, "Hox ${ }_{\mathrm{a}}$ " represents the crystallized geometry while "Hox ${ }_{\mathrm{b}}$ " is characterized by a partly rotated, distal $\mathrm{CN}^{-}$ligand. (B) Plotting data from Fig. 3 for $\left[\right.$ Hox-CO] at $t_{1}$ (inhibition) against $[\mathbf{H o x}-\mathbf{C O}]$ at $\mathrm{t}_{2}$ (reactivation) illustrates that ADT and ODT have a high CO affinity whereas PDT is relatively CO insensitive. Cofactor variants occupying the upper left of the graph show mixed characteristics. A two-step reaction model with a reversible geometry change followed by $\mathrm{CO}$ binding reasonably reproduces the observed behavior (dashed line, see Fig. S9 and the legend for computational details and underlying rate constants that yielded the theoretical Hox-CO concentration values).

We suggest that oscillations of the Hox geometry determine the apparent Hox-CO population and assign the effects of dithiolate exchange to a gradual de-stabilization of a Hox isomer with slight ligand rearrangements at $\mathrm{Fe}_{\mathrm{d}}$ ("Hox $\mathrm{x}_{\mathrm{b}}$ "). This view is supported by the relative energies of the two Hox conformers as derived from DFT calculations, which suggest considerable stabilization of the crystallographic conformation $\left(\operatorname{Hox}_{\mathrm{a}}\right)$ in $\mathbf{H o x}$, but stabilization of the 
conformation with an apical $\mathrm{CN}^{-}\left(a \mathrm{CN}^{-}\right)$at $\mathrm{Fe}_{\mathrm{d}}$ in $\mathbf{H o x}-\mathbf{C O}$, as well as destabilization of the $a \mathrm{CN}^{-}$conformation of Hox-CO in the non-ADT cofactor variants (see caption of Fig. S9 for details). While simulating absolute rates of $\mathrm{CO}$ inhibition and reactivation is not possible at this stage, we aimed at a qualitative description of the kinetic differences between cofactor variants. More complex kinetic models are certainly conceivable, but cannot be uniquely designed at present due to the lack of information on protein-cofactor interactions and other kinetic processes. The observed differences in $\mathrm{CO}$ inhibition and reactivation are hardly compatible with an apical CO ligand. Weakening of Hox-CO thus is attributed to the lack of hydrogen bonding between the dithiolate head group and an apical $\mathrm{CN}^{-}$ligand. However, the reactivation kinetics indicate a higher degree of complexity. This possibly includes electrostatic attraction $(\mathrm{ODT}, \mathrm{SDT})^{14}$, steric repulsion between the apical ligand and the dithiolate head group (PDT) ${ }^{15}$, as well as differences in electron density distribution across the diiron site (PDS). ${ }^{33}$ A notable spectroscopic feature is the lack of larger changes in the $\mathrm{CN}^{-}$frequencies among the $\mathrm{CO}$ inhibited cofactor variants (Fig. S2 and Table S2). Previously, the deletion of a putative hydrogen bond donor to $\mathrm{Fe}_{\mathrm{p}}-\mathrm{CN}^{-}$shifted the corresponding IR bands by $\sim 20 \mathrm{~cm}^{-1}$ to lower frequencies. ${ }^{36}$ Whether outer-sphere hydrogen bonding (i.e. to adjacent amino acid residues or water molecules) may compensate for inner-sphere hydrogen bonding in cofactor variants ODT and EDT was probed in the next step.

Outer-sphere stabilization of Hox-CO. Cysteine 169 functions as a proton relay between the H-cluster and water cluster W1. It represents a likely hydrogen-bond donor in the vicinity of the H-cluster. To probe the influence of $\mathrm{C} 169$ on $\mathrm{CO}$ affinity, we produced site-directed mutagenesis variants with a cysteine/ alanine exchange. HYDA1-C169A was reconstituted with ADT, ODT, or EDT cofactors and analyzed by in situ ATR FTIR spectroscopy (Fig. 5 and Fig. S10). In comparison to wild-type enzyme, the spectra of $\mathbf{H o x}$ exhibited a mean $\mathrm{CO} / \mathrm{CN}^{-}$downshift of only $\sim 3 \mathrm{~cm}^{-1}$ whereas the Hox-CO signature of the HYDA1-C169A cofactor variants 
indicated much stronger shifts to lower frequencies. For example, the coupled CO modes $\beta$ and $\delta$ shift by $8-12 \mathrm{~cm}^{-1}$ and $24-28 \mathrm{~cm}^{-1}$, respectively. Band $\gamma$ that comprises significant contributions from the proximal CO ligand did not change significantly. The difference spectra for ADT, ODT, and EDT in Figure 5 show that the Hox-CO signature of HYDA1-C169A is not the same; however, the dithiolate-specific IR band up-shifts observed in CO-inhibited wildtype enzyme (Fig. 2B) were found to be largely remedied. The Hox-CO spectrum of HYDA1C169A ADT was hardly affected by the amino acid exchange.

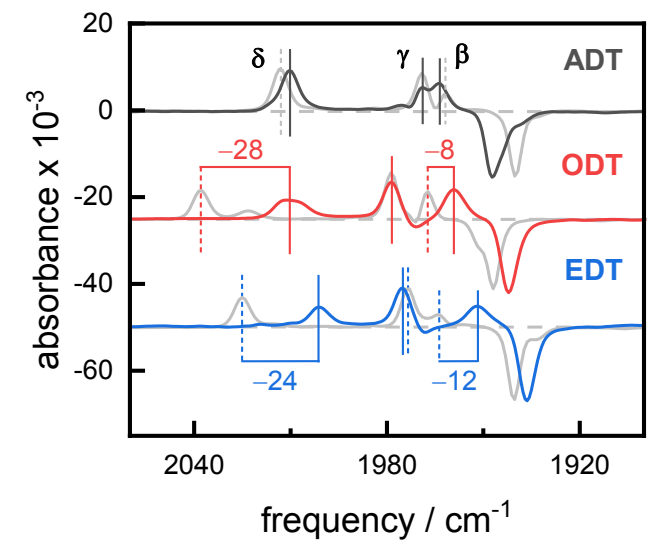

Figure 5. ATR FTIR difference spectra of the Hox $\rightarrow$ Hox-CO conversion. Spectra of the C169A variant of HYDA1 are shown as colored lines, grey spectra depict wild-type enzyme. The frequencies of the $\mathrm{CO}$ vibrational modes of Hox-CO (positive bands $\beta, \gamma$, and $\delta$ ) are sensitive to the H-clusters' geometry. Negative bands are assigned to Hox. Significant downshifts are indicated in $\mathrm{cm}^{-1}$ (IR bands $\beta$ and $\delta$, predominantly). Only limited differences in Hox-CO were observed between native HYDA1 and HYDA1-C169 (ADT).

We recently solved the crystal structure of CPI-C299A in oxidized form (equivalent to HYDA1-C169A). ${ }^{11}$ Here, the cysteine is replaced by a water molecule, W* (Fig. S11). Although CPI-C299A was not crystalized in CO-inhibited form, no variation of internal water was observed upon $\mathrm{CO}$ inhibition of native enzyme ${ }^{20,21}$ suggesting conserved localization of $\mathrm{W}^{*}$ in both Hox and Hox-CO. This water species may act as a hydrogen bond donor to the 
apical $\mathrm{CN}^{-}$ligand of Hox-CO when inner-sphere hydrogen bonding is impeded (i.e., in ODT and EDT). The similar IR signatures of the CO-inhibited C169A variants (Fig. 5) suggest an unconstrained ligand orientation reflecting the structural flexibility of the water molecule acting as a hydrogen bond donor. Furthermore, hydrogen bonding to $\mathrm{W}^{*}$ (instead of C169) may explain the lack of significant differences in the $\mathrm{CN}^{-}$regime "rescuing" the native Hox-CO signature. We conclude that the hydrogen-bonding network between polar, apical ligands at the $\mathrm{H}$-cluster and the adjacent cysteine sidechain or neighboring water species is an important determinant of the diiron site geometry in the non-ADT variants.

Hydrogen Oxidation Kinetics. To investigate the geometry of the H-cluster in reduced form, we explored the reaction with $\mathrm{H}_{2}$ of different HYDA1 cofactor variants by in situ ATR FTIR spectroscopy (Fig. 6). In the presence of $\mathrm{H}_{2}$, native ADT enzyme revealed a complex mixture of Hred' and Hred/Hsred at pH 8 (top left) while near-quantitative Hhyd formation was observed at $\mathrm{pH} 4$ (top right). ${ }^{29}$ Independent of the $\mathrm{pH}$, cofactor variants PDT and PDS formed no other redox species than Hred' whereas SDT enzyme did not react with $\mathrm{H}_{2}$ at all (Fig. S12). ${ }^{14,15}$ ODT and EDT revealed a large population of Hred' and Hhyd already at $\mathrm{pH} 8 .^{28}$ The

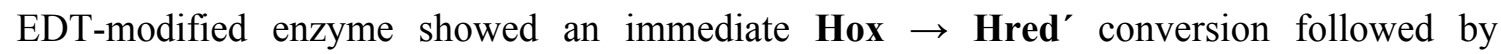
progressive enrichment of Hhyd over Hred' (bottom left). These processes occur simultaneously in HYDA1-ODT (bottom right). For subsequent replacement of $\mathrm{H}_{2}$ with $\mathrm{N}_{2}$, native enzyme exhibited the slowest Hhyd decrease, HYDA1-EDT the fastest decrease, and cofactor variant ODT adopted medium-speed decay kinetics (Fig. S13). Notably, Hred and Hsred were exclusively observed in HYDA1-ADT, which illustrates the need for efficient proton transfer in the reduction of the diiron site. 


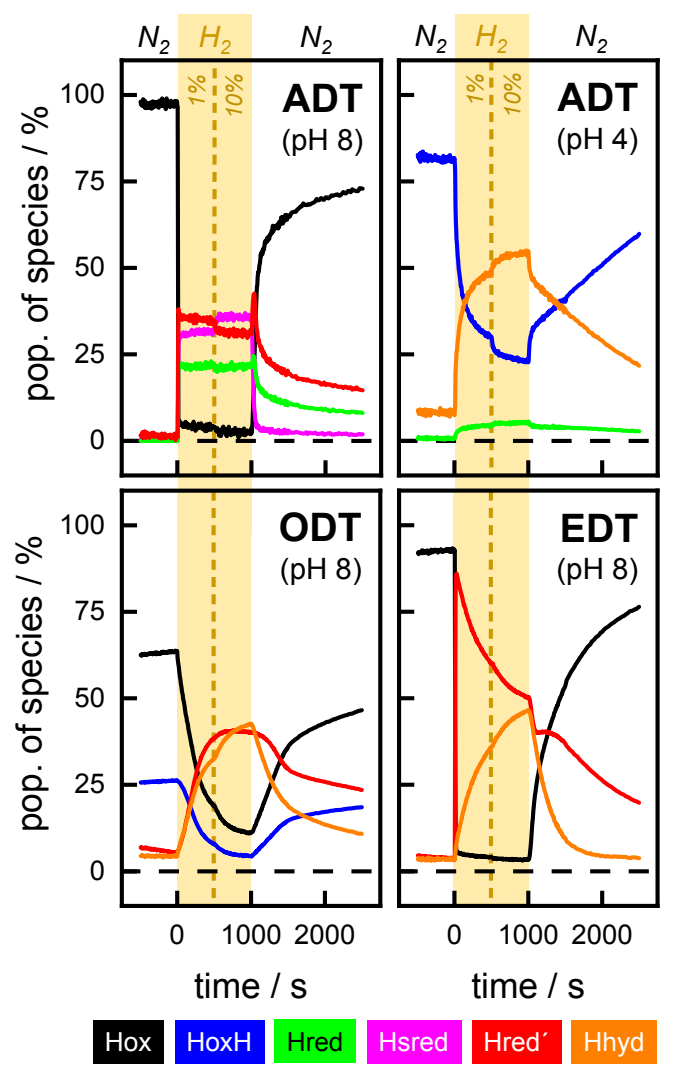

Figure 6. $\mathrm{H}_{2}$ oxidation kinetics. Changes of H-cluster populations in HYDA1 enzyme in the presence of $0 \%, 1 \%$, or $10 \% \mathrm{H}_{2}$ in the $\mathrm{N}_{2}$ carrier gas. Top left: In native enzyme, exposure to $\mathrm{H}_{2}$ caused an immediate accumulation of reduced cofactor states Hred/ Hsred and Hred' at the expense of Hox ( $\mathrm{pH}$ 8). When $\mathrm{H}_{2}$ was removed from the gas phase, a short-lived increase of Hred and Hred' at the expense of Hsred was observed. Top right: At $\mathrm{pH} 4$, native enzyme predominantly formed Hhyd and traces of Hred out of HoxH. Bottom left: Cofactor variant ODT was found to accumulate Hred' and Hhyd slowly and simultaneously. Even at pH 8, the oxidized sample comprised $\sim 25 \%$ HoxH. Bottom right: Cofactor variant EDT reacts much faster with $\mathrm{H}_{2}$ than ODT, first converting from Hox to Hred' and thereafter from Hred' to Hhyd (pH 8). Both ODT and EDT show no traces of Hred/ Hsred. The persistence of Hhyd in the absence of $\mathrm{H}_{2}$ decreases in the following order: ADT $>$ ODT $>$ EDT. 
The H-cluster binds an apical hydride ligand $\left(a \mathrm{H}^{-}\right)$at the distal iron ion in Hhyd. ${ }^{27-29}$ It seems reasonable to assume hydrogen bonding between $a \mathrm{H}^{-}$and ADT-NH stabilizing the charged apical ligand, similar to the situation in Hox-CO (see above). However, to understand the formation and stabilization of Hhyd in cofactor variants ODT and EDT, both thermodynamic and kinetic considerations must be taken into account. High proton concentrations ${ }^{11,29}$ or partly impaired proton transfer activity ${ }^{27,28}$ to the diiron site have been exploited to accumulate Hhyd in functional enzyme. Hydride formation in ODT and EDT is facilitated by outer-sphere stabilization between $a \mathrm{H}^{-}$and the protein environment, most likely compensating for the lack of an inner-sphere hydrogen bond donor (i.e., ADT-NH). In contrast to HYDA1-C169A, the double variants HYDA1-C169A ODT and EDT were found to be completely unreactive with $\mathrm{H}_{2}$ (Fig. S12). Revisiting CO inhibition is informative here. The double variants were easily inhibited by CO, explained by the presence of an additional water molecule in HYDA1-C169A, $\mathrm{W}^{*}$ (Fig. 5). Although a similar arrangement should be able to stabilize the hydride state, heterolytic cleavage of $\mathrm{H}_{2}$ was not observed. This illustrates the role of proton transfer in the accumulation of reduced species like Hhyd and allows concluding that the geometry of the Hcluster is determined by both hydrogen bonding and proton transfer.

Direct evidence for a similar mechanism of Hhyd and Hox-CO stabilization was derived from concerted $\mathrm{H}_{2}$ and $\mathrm{CO}$ treatments on HYDA1 (Fig. 7). The top left panel shows the concomitant decrease of Hred/Hsred and $\mathbf{H r e d}^{\prime}$ at $1 \%$ or $10 \% \mathrm{CO}$ in $\mathrm{H}_{2}$ carrier gas in native enzyme (pH 8). Different to inhibition under oxidizing conditions, $\mathrm{CO}$ inhibition in the presence of $\mathrm{H}_{2}$ yielded a combination of Hred'-CO and Hox-CO, indicating an incomplete oxidation. Compared to Fig. 3A, native enzyme reacts significantly slower with $\mathrm{CO}$ and recovers from inhibition about four times faster under $\mathrm{H}_{2}$ (Fig. S14). This reflects the higher affinity of $\mathrm{CO}$ compared to $\mathrm{H}_{2}$ of the ADT H-cluster. ${ }^{41}$ Furthermore, a small yet significant fraction of Hred/Hsred remains to be stable with $1 \% \mathrm{CO}$ whereas Hred' is lost completely under these 
conditions (Fig. S15). While Hred' is characterized by $\mu \mathrm{CO}$ ligand with an open coordination site at $\mathrm{Fe}_{\mathrm{d}}{ }^{16-18}$ reduction of the diiron site apparently provides mild protection against exogenous CO. The ability of native enzyme to accumulate H-cluster intermediates with a reduced diiron site (Hred/Hsred) likely contributes to the enhanced reactivation from COinhibition in the presence of $\mathrm{H}_{2}$, which is not observed in HYDA1-ODT (see Fig. S14). It remains to be evaluated if this is due to changes in redox state or caused by conformational changes as suggested earlier. ${ }^{22}$

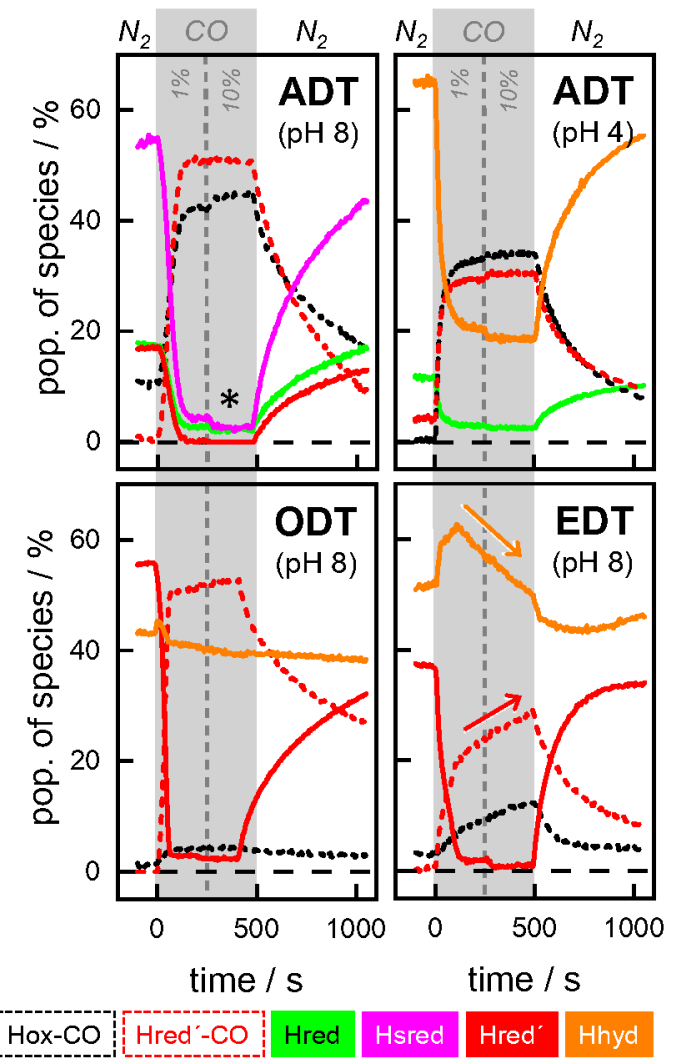

Figure 7. $\mathrm{CO}$ inhibition and reactivation in the presence of $\mathbf{H}_{2}$. Changes of H-cluster populations in HYDAl enzyme in the presence of $0 \%, 1 \%$, or $10 \% \mathrm{H}_{2}$ (carrier gas $\mathrm{H}_{2}$ ). Top left: In native enzyme ( $\mathrm{pH} 8)$, exposure to $\mathrm{CO}$ caused an immediate decrease of reduced cofactor states Hred/ Hsred and Hred'. Asterisks: about 5\% Hred/ Hsred remain stable under 1\% CO (see Fig. S15). Top right: The hydride state predominantly formed at $\mathrm{pH} 4$ is 
diminished to $\sim 20 \%$ under CO. Bottom left: In cofactor variant ODT an increase of Hred'-CO over Hred' was observed upon CO exposure ( $\mathrm{pH} 8)$, but virtually no decrease of Hhyd. Bottom right: In comparison, slow changes in Hhyd in the presence of CO indicate that Hhyd in EDT was less stable than in ODT.

Distinct protection against $\mathrm{CO}$ was observed when the H-cluster was locked in the hydride state, i.e. at $\mathrm{pH} 4$ (Fig. 7, top right panel). In the presence of $10 \% \mathrm{CO}$, approximately $>20 \%$ Hhyd prevailed. This effect was found to be even more pronounced in the cofactor variants, even at alkaline $\mathrm{pH}$ values. For example, HYDA1-ODT showed conversion of Hred' to Hred'-CO but virtually no decrease of Hhyd (bottom left) whereas a very slow conversion of Hhyd into COinhibited species was notable in HYDA1-EDT (bottom right). The higher stability of the hydride state in cofactor variant ODT vs. EDT agrees well with decrease kinetics of Hhyd (Fig. S13) and Hox-CO (Fig. 3) as discussed above. Our systematic evaluation of the reactivity of HYDA1 cofactor variants with $\mathrm{CO}$ and $\mathrm{H}_{2}$ emphasizes that inner coordination sphere interactions are a major determinant for stabilization of apical ligands in both Hox-CO and Hhyd.

\section{CONCLUSIONS}

Our experimental and computational analysis of the [FeFe]-hydrogenase from C. reinhardtii consistently implies that the $\mathrm{CO} / \mathrm{CN}^{-}$ligand dynamics of the $\mathrm{H}$-cluster are governed by proton transfer and hydrogen-bonding interactions at the inner coordination sphere (Fig. 8). We propose an intrinsically flexible diiron site geometry ${ }^{19,40}$ that facilitates stabilization of polar ligands at the distal iron ion in both catalytic intermediates (Hhyd) and inhibited species (HoxCO). Comparing $\mathrm{H}_{2}$ oxidation and $\mathrm{CO}$ inhibition allows dissecting the influence of proton transfer and hydrogen bonding on the geometry of the H-cluster. 


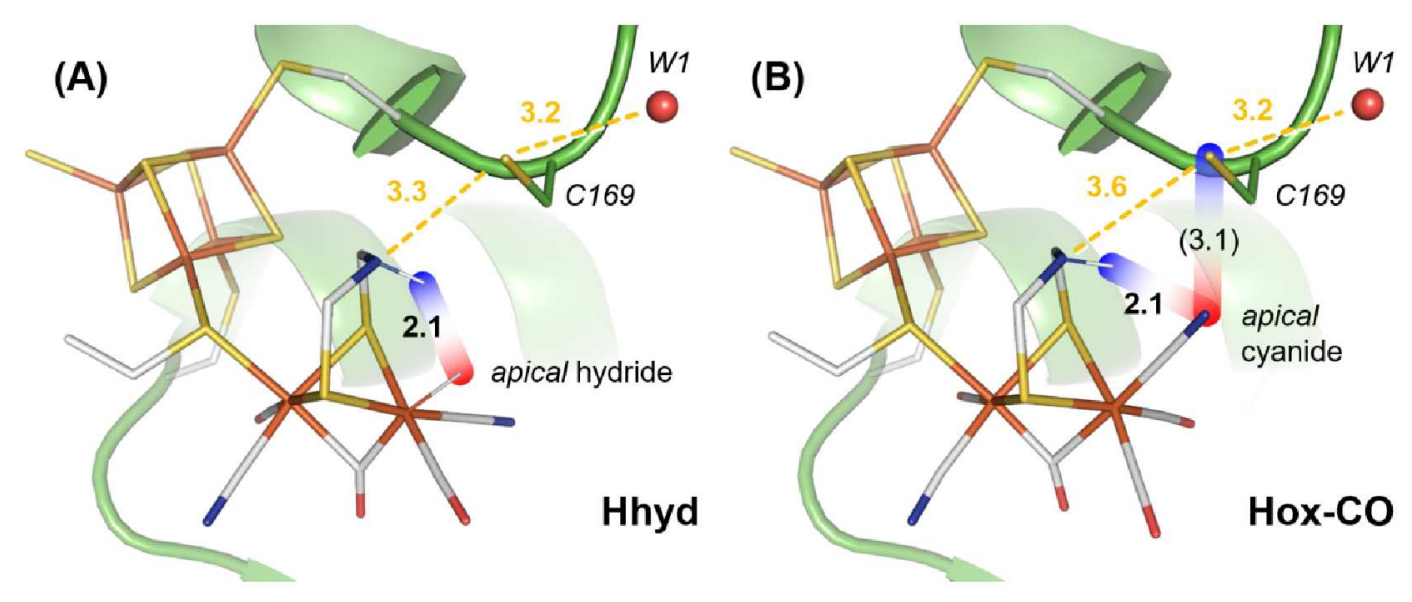

Figure 8. Proton transfer and hydrogen bonding at the H-cluster. DFT models of the Hcluster in the Hhyd and Hox-CO state were superposed with the crystal structure of CPI (pdb entry $4 \mathrm{XDC}$ ). Dashed lines suggest potential proton transfer trajectories. Blue and red color indicate positive and negative (partial) charges, respectively. All distances are given in $10 \mathrm{~m}^{-10}$ (A). (A) In native enzyme, inner-sphere hydrogen bonding stabilizes the apical hydride ligand of Hhyd. Variants with no proton transfer activity did not accumulate Hhyd. (B) The COinhibited state Hox-CO is stabilized by either inner or outer coordination sphere hydrogenbonding to the apical cyanide ligand, depending on the nature of the dithiolate headgroup. Accumulation of Hox-CO is independent of proton transfer.

For the native enzyme, stabilization is mainly achieved by inner-sphere hydrogen bonding between ADT-NH and the apical hydride ligand of Hhyd or the apical cyanide ligand of HoxCO. For cofactor variants with a less polar dithiolate group, stabilization of a particular diiron site geometry is determined by outer coordination sphere interactions, i.e. hydrogen-bonding to adjacent amino acid side chains and/or water species (Fig. 8). Our findings further suggest different H-cluster geometries for Hox/Hred' and Hred/Hsred, emphasizing the need for combined crystallographic and spectroscopic studies on the reduced or " $\mathrm{H}_{2}$-inhibited" states of [FeFe]-hydrogenases. ${ }^{30}$ Comparative $\mathrm{CO}$ inhibition and $\mathrm{H}_{2}$ oxidation experiments helped identifying such correlations and facilitated a detailed understanding of hydrogen bonding and 


\section{MATERIAL AND METHODS}

Artificial maturation and protein crystallography. $[\mathrm{FeFe}]$-hydrogenase apo-protein from $C$. reinhardtii (HYDA1) and C. pasteurianum (CPI) was expressed in in Escherichia coli (BL21(DE3)- $\Delta$ iscR) and purified as previously described; cofactor synthesis and in vitro maturation of protein was performed following established protocols. ${ }^{32,33}$ Diffraction data on protein crystals of the semisynthetic CPI hydrogenase EDT were collected at $100 \mathrm{~K}$ at beamline ESRF-BM30A (Grenoble, France) and processed as reported earlier. ${ }^{8}$ The crystal structure was deposited in the Protein Data Bank under accession code 6H63. Crystallographic data is summarized in Table S3. See Supporting Information for further experimental details.

ATR FTIR spectroscopy and data evaluation. Infrared spectra were recorded on protein films using FTIR spectroscopy in attenuated total reflection configuration on a Bruker Tensor27 spectrometer. ${ }^{18} \mathrm{H}$-cluster states were populated in the presence of defined compositions of $\mathrm{N}_{2}$, 
$\mathrm{CO}$, or $\mathrm{H}_{2}$ in a humidified, $\mathrm{pH}$-controlled gas stream ("aerosol”). To monitor the H-cluster state conversions in time, IR spectra were collected in real time with a temporal resolution of $1-5 \mathrm{~s}$. Data evaluation involved normalization of spectra followed by a global fit approach in the $\mathrm{CO} / \mathrm{CN}^{-}$regime to determine cofactor state populations. ${ }^{18}$ See Supporting Information for further details.

Transient IR spectroscopy. Samples of HYDA1 ADT, ODT, and EDT variants were mixed (3 $\mu \mathrm{L}$ of $\sim 1 \mathrm{mM}$ protein), dehydrated under $\mathrm{CO}$ gas on a $\mathrm{BaF}_{2}$ window, rehydrated via vapor diffusion, and sealed with a second $\mathrm{BaF}_{2}$ window. Photolysis of the exogenous $\mathrm{CO}$ ligand was induced by a $10 \mathrm{~ns}$ flash $\left(\sim 90 \mathrm{~mJ} / \mathrm{cm}^{2}, 450 \mathrm{~nm}\right)$ from an optical parametric oscillator pumped by the third harmonic of a Nd:YAG laser (Quanta-Ray). IR transients $\left(2000-2045 \mathrm{~cm}^{-1}, 1 \mathrm{~cm}^{-1}\right.$ steps, 100 repetitions at $1 \mathrm{~Hz}$ each) were recorded on a homebuilt continuous-wave quantumcascade laser (QCL) spectrometer. ${ }^{39}$ See Supporting Information for further details.

Computational procedures. Density functional theory and quantum mechanics/ molecular mechanics calculations (BP86 or TPSSh functionals and TZVP basis-set, broken-symmetry approach for geometry-optimization and antiferromagnetic couplings calculation, ONIOM method and universal force field in QM/MM) on model structures (Fig. S16) were carried out using Gaussian09 as reported in ref. 50. Vibrational frequencies were derived from normal mode analysis of relaxed structures. Numerical kinetic simulations were performed with the CAIN ordinary differential equation solver (available at http://cain.sourceforge.net). See Supporting Information (computational procedures and references therein, Figs. S5, S6, S8, and S15) for further details. 


\section{SUPPORTING INFORMATION}

Supporting experimental procedures; Supporting computational procedures; Comparison of ADT and EDT; Comparison of Hox/HoxH and Hox-CO/HoxH-CO; Auto-oxidation in the absence of H2; Experimental CO band frequency differences; Calculation of vibrational frequencies; Reproducibility and variance; Transient IR spectroscopy; Kinetic simulations; Absolute spectra for HYDA1-C169A; Comparison of native CPI and CPI-C299A; Spectra of all cofactor variants in the presence of $\mathrm{H}_{2}$; Stability of Hhyd in the absence of $\mathrm{H}_{2}$; Reactivation from CO-inhibition in ADT and ODT; Durability of Hsred in the presence of $\mathrm{H}_{2}$ and $\mathrm{CO}$; Computational structures; IR-frequencies for H-cluster species with a Hox-like diiron site geometry (table); IR-frequencies for CO-inhibited H-cluster species (table); Data collection and refinement statistics of crystal structure CPI-EDT (table); Fitting parameters (table); XYZ coordinates (table).

\section{ACKNOWLEDGEMENTS}

We thank all reviewers for their valuable input. STS acknowledges M.-H. Chiang for inspiring discussions. STS is funded by the DFG within the framework of priority program 1927 (1554/51). $\mathrm{MH}$ and JH acknowledge financial support within UniSysCat (Cluster of Excellence Berlin). JD, MW, and TH acknowledge financial support from the Volkswagen Stiftung (Az 93412), the RESOLV Cluster of Excellence Bochum (EXC 1069), and the China Scholarship Council. FW and UPA thank the DFG (AP242/2-1), the Fraunhofer Internal Programs (ATTRACT 097602175), and the Studienstiftung des Deutschen Volkes for financial support. We thank the staff of beamline BM30A at the European Synchrotron Radiation Facility (ESRF) for technical support during data collection. 


\section{REFERENCES}

(1) Lubitz, W.; Ogata, H.; Ru, O.; Reijerse, E. Hydrogenases. Chem. Rev. 2014, 114 (8), 4081-4148. https://doi.org/10.1021/cr4005814.

(2) Vincent, K. A.; Parkin, A.; Lenz, O.; Albracht, S. P. J.; Fontecilla-Camps, J. C.; Cammack, R.; Friedrich, B.; Armstrong, F. A. Electrochemical Definitions of O2 Sensitivity and Oxidative Inactivation in Hydrogenases. J. Am. Chem. Soc. 2005, 127 (51), 18179-18189. https://doi.org/10.1021/ja055160v.

(3) Stripp, S. T.; Goldet, G.; Brandmayr, C.; Sanganas, O.; Vincent, K. A.; Haumann, M.; Armstrong, F. A.; Happe, T. How Oxygen Attacks [FeFe] Hydrogenases from Photosynthetic Organisms. Proc. Natl. Acad. Sci. U. S. A. 2009, 106 (41), 1733117336. https://doi.org/10.1073/pnas.0905343106.

(4) De Lacey, A. L.; Stadler, C.; Fernandez, V. M.; Hatchikian, E. C.; Fan, H.-J.; Li, S.; Hall, M. B. IR Spectroelectrochemical Study of the Binding of Carbon Monoxide to the Active Site of Desulfovibrio Fructosovorans Ni-Fe Hydrogenase. J. Biol. Inorg. Chem. 2002, 7 (3), 318-326. https://doi.org/10.1007/s00775-001-0301-7.

(5) Roseboom, W.; De Lacey, A. L.; Fernandez, V. M.; Hatchikian, E. C.; Albracht, S. P. J. The Active Site of the [FeFe]-Hydrogenase from Desulfovibrio Desulfuricans. II. Redox Properties, Light Sensitivity and CO-Ligand Exchange as Observed by Infrared Spectroscopy. J. Biol. Inorg. Chem. 2006, 11 (1), 102-118. https://doi.org/10.1007/s00775-005-0040-2.

(6) Peters, J. W.; Lanzilotta, W. N.; Lemon, B. J.; Seefeldt, L. C. X-Ray Crystal Structure of the Fe-Only Hydrogenase $(\mathrm{CpI})$ from Clostridium Pasteurianum to 1.8 Angstrom Resolution. Science 1998, 282 (5395), 1853-1858. https://doi.org/10.1126/science.282.5395.1853.

(7) Nicolet, Y.; Piras, C.; Legrand, P.; Hatchikian, C. E.; Fontecilla-Camps, J. C. Desulfovibrio Desulfuricans Iron Hydrogenase: The Structure Shows Unusual Coordination to an Active Site Fe Binuclear Center. Structure 1999, 7 (1), 13-23. https://doi.org/10.1016/S0969-2126(99)80005-7.

(8) Esselborn, J.; Muraki, N.; Klein, K.; Engelbrecht, V.; Metzler-Nolte, N.; Apfel, U.-P.; Hofmann, E.; Kurisu, G.; Happe, T. A Structural View of Synthetic Cofactor Integration into [FeFe]-Hydrogenases. Chem. Sci. 2016, 7, 959-968. https://doi.org/10.1039/C5SC03397G.

(9) Silakov, A.; Reijerse, E. J.; Albracht, S. P. J.; Hatchikian, E. C.; Lubitz, W. The Electronic Structure of the H-Cluster in the [FeFe]-Hydrogenase from Desulfovibrio Desulfuricans: A Q-Band 57Fe-ENDOR and HYSCORE Study. J. Am. Chem. Soc. 2007, 129 (37), 11447-11458. https://doi.org/10.1021/ja072592s.

(10) Singleton, M. L.; Bhuvanesh, N.; Reibenspies, J. H.; Darensbourg, M. Y. Synthetic Support of De Novo Design: Sterically Bulky [FeFe]-Hydrogenase Models. Angew. Chemie Int. Ed. 2008, 47 (49), 9492-9495. https://doi.org/10.1002/anie.200803939.

(11) Duan, J.; Senger, M.; Esselborn, J.; Engelbrecht, V.; Wittkamp, F.; Apfel, U.-P.; Hofmann, E.; Stripp, S. T.; Happe, T.; Winkler, M. Crystallographic and Spectroscopic Assignment of the Proton Transfer Pathway in [FeFe]-Hydrogenases. Nat. Commun. 2018, 9, 4726. https://doi.org/10.1038/s41467-018-07140-x. 
(12) Silakov, A.; Wenk, B.; Reijerse, E.; Lubitz, W. 14N HYSCORE Investigation of the HCluster of [FeFe] Hydrogenase: Evidence for a Nitrogen in the Dithiol Bridge. Phys. Chem. Chem. Phys. 2009, 11 (31), 6553-6554. https://doi.org/10.1039/b913085n.

(13) Adamska-Venkatesh, A.; Krawietz, D.; Siebel, J. F.; Weber, K.; Happe, T.; Reijerse, E.; Lubitz, W. New Redox States Observed in [FeFe] Hydrogenases Reveal Redox Coupling within the H-Cluster. J. Am. Chem. Soc. 2014, 136 (32), 11339-11346. https://doi.org/10.1021/ja503390c.

(14) Siebel, J. F.; Adamska-Venkatesh, A.; Weber, K.; Rumpel, S.; Reijerse, E.; Lubitz, W. Hybrid [FeFe]-Hydrogenases with Modified Active Sites Show Remarkable Residual Enzymatic Activity. Biochemistry 2015, 54 (7), 1474-1483. https://doi.org/10.1021/bi501391d.

(15) Sommer, C.; Rumpel, S.; Roy, S.; Farès, C.; Artero, V.; Fontecave, M.; Reijerse, E.; Lubitz, W. Spectroscopic Investigations of a Semi-Synthetic [FeFe] Hydrogenase with Propane Di-Selenol as Bridging Ligand in the Binuclear Subsite: Comparison to the Wild Type and Propane Di-Thiol Variants. J. Biol. Inorg. Chem. 2018, 23 (3), 481491. https://doi.org/10.1007/s00775-018-1558-4.

(16) Katz, S.; Noth, J.; Horch, M.; Shafaat, H. S.; Happe, T.; Hildebrandt, P.; Zebger, I. Vibrational Spectroscopy Reveals the Initial Steps of Biological Hydrogen Evolution. Chem. Sci. 2016, 7, 6746-6752. https://doi.org/10.1039/C6SC01098A.

(17) Senger, M.; Laun, K.; Wittkamp, F.; Duan, J.; Haumann, M.; Happe, T.; Winkler, M.; Apfel, U.-P.; Stripp, S. T. Proton-Coupled Reduction of the Catalytic [4Fe-4S] Cluster in [FeFe]-Hydrogenases. Angew. Chemie Int. Ed. 2017, 56 (52), 16503-16506. https://doi.org/10.1002/anie.201709910.

(18) Senger, M.; Mebs, S.; Duan, J.; Shulenina, O.; Laun, K.; Kertess, L.; Wittkamp, F.; Apfel, U.-P.; Happe, T.; Winkler, M.; et al. Protonation/Reduction Dynamics at the [4Fe-4S] Cluster of the Hydrogen-Forming Cofactor in [FeFe]-Hydrogenases. Phys. Chem. Chem. Phys. 2018, 20, 3128-3140. https://doi.org/10.1039/C7CP04757F.

(19) Senger, M.; Mebs, S.; Duan, J.; Wittkamp, F.; Apfel, U.-P.; Heberle, J.; Haumann, M.; Stripp, S. T. Stepwise Isotope Editing of [FeFe]-Hydrogenases Exposes Cofactor Dynamics. Proc. Natl. Acad. Sci. U. S. A. 2016, 113 (30), 8454-8459. https://doi.org/10.1073/pnas.1606178113.

(20) Lemon, B. J.; Peters, J. W. Binding of Exogenously Added Carbon Monoxide at the Active Site of the Iron-Only Hydrogenase (CpI) from Clostridium Pasteurianum. Biochemistry 1999, 38 (40), 12969-12973. https://doi.org/10.1021/bi9913193.

(21) Lemon, B. J.; Peters, J. W. Photochemistry at the Active Site of the Carbon Monoxide Inhibited Form of the Iron-Only Hydrogenase (CpI). J. Am. Chem. Soc. 2000, 122 (15), 3793-3794. https://doi.org/10.1021/ja9943703.

(22) Mebs, S.; Senger, M.; Duan, J.; Wittkamp, F.; Apfel, U.-P.; Happe, T.; Winkler, M.; Stripp, S. T.; Haumann, M. Bridging Hydride at Reduced H-Cluster Species in [FeFe]Hydrogenases Revealed by Infrared Spectroscopy, Isotope Editing, and Quantum Chemistry. J. Am. Chem. Soc. 2017, 139 (35), 12157-12160. https://doi.org/10.1021/jacs.7b07548.

(23) Nicolet, Y.; De Lacey, A. L.; Vernède, X.; Fernandez, V. M.; Hatchikian, E. C.; Fontecilla-Camps, J. C. Crystallographic and FTIR Spectroscopic Evidence of Changes 
in Fe Coordination upon Reduction of the Active Site of the Fe-Only Hydrogenase from Desulfovibrio Desulfuricans. J. Am. Chem. Soc. 2001, 123 (8), 1596-1601. https://doi.org/10.1021/ja0020963.

(24) Adamska-Venkatesh, A.; Silakov, A.; Lambertz, C.; Rüdiger, O.; Happe, T.; Reijerse, E.; Lubitz, W. Identification and Characterization of the "Super-Reduced" State of the H-Cluster in [FeFe] Hydrogenase: A New Building Block for the Catalytic Cycle?

Angew. Chemie Int. Ed. 2012, 51 (46), 11458-11462.

https://doi.org/10.1002/anie.201204800.

(25) Sommer, C.; Adamska-Venkatesh, A.; Pawlak, K.; Birrell, J. A.; Rüdiger, O.; Reijerse, E. J.; Lubitz, W. Proton Coupled Electronic Rearrangement within the H-Cluster as an Essential Step in the Catalytic Cycle of [FeFe] Hydrogenases. J. Am. Chem. Soc. 2017, 139 (4), 1440-1443. https://doi.org/10.1021/jacs.6b12636.

(26) Ratzloff, M. W.; Artz, J. H.; Mulder, D. W.; Collins, R. T.; Furtak, T. E.; King, P. W. $\mathrm{CO}$-Bridged H-Cluster Intermediates in the Catalytic Mechanism of [FeFe]-

Hydrogenase CaI. J. Am. Chem. Soc. 2018, 140 (24), 7623-7628.

https://doi.org/10.1021/jacs.8b03072.

(27) Mulder, D. W.; Guo, Y.; Ratzloff, M. W.; King, P. W. Identification of a Catalytic Iron-Hydride at the H-Cluster of [FeFe]-Hydrogenase. J. Am. Chem. Soc. 2016, 139 (1), 83-86. https://doi.org/10.1021/jacs.6b11409.

(28) Reijerse, E. J.; Pham, C. C.; Pelmenschikov, V.; Gilbert-wilson, R.; AdamskaVenkatesh, A.; Siebel, J. F.; Gee, L. B.; Yoda, Y.; Tamasaku, K.; Lubitz, W.; et al. Direct Observation of an Iron-Bound Terminal Hydride in [FeFe]- Hydrogenase by Nuclear Resonance Vibrational Spectroscopy. J. Am. Chem. Soc. 2017, 139 (12), 4306-4309. https://doi.org/10.1021/jacs.7b00686.

(29) Winkler, M.; Senger, M.; Duan, J.; Esselborn, J.; Wittkamp, F.; Hofmann, E.; Apfel, U.-P.; Stripp, S. T.; Happe, T. Accumulating the Hydride State in the Catalytic Cycle of [FeFe]-Hydrogenases. Nat. commun. 2017, 8 (16115), 1-7. https://doi.org/10.1038/ncomms16115.

(30) Haumann, M.; Stripp, S. T. The Molecular Proceedings of Biological Hydrogen Turnover. Acc. Chem. Res. 2018, 51 (8), 1755-1763. https://doi.org/10.1021/acs.accounts.8b00109.

(31) Berggren, G.; Adamska-Venkatesh, A.; Lambertz, C.; Simmons, T. R.; Esselborn, J.; Atta, M.; Gambarelli, S.; Mouesca, J.-M.; Reijerse, E. J.; Lubitz, W.; et al. Biomimetic Assembly and Activation of [FeFe]-Hydrogenases. Nature 2013, 499 (7456), 66-69. https://doi.org/10.1038/nature12239.

(32) Esselborn, J.; Lambertz, C.; Adamska-Venkatesh, A.; Simmons, T.; Berggren, G.; Noth, J.; Siebel, J. F.; Hemschemeier, A.; Artero, V.; Reijerse, E.; et al. Spontaneous Activation of [FeFe]-Hydrogenases by an Inorganic [2Fe] Active Site Mimic. Nat. Chem. Biol. 2013, 9, 607-609. https://doi.org/10.1038/nchembio.1311.

(33) Kertess, L.; Wittkamp, F.; Sommer, C.; Esselborn, J.; Rüdiger, O.; Reijerse, E.; Hofmann, E.; Lubitz, W.; Winkler, M.; Happe, T.; et al. Chalcogenide Substitution in the [2Fe]-Cluster of [FeFe]-Hydrogenases Conserves High Enzymatic Activity. Dalt. Trans. 2017, 46, 16947-16958. https://doi.org/10.1039/C7DT03785F.

(34) Ginovska-Pangovska, B.; Dutta, A.; Reback, M. L.; Linehan, J. C.; Shaw, W. J. 
Beyond the Active Site: The Impact of the Outer Coordination Sphere on Electrocatalysts for Hydrogen Production and Oxidation. Acc. Chem. Res. 2014, 47 (8), 2621-2630. https://doi.org/10.1021/ar5001742.

(35) Knörzer, P.; Silakov, A.; Foster, C. E.; Armstrong, F. A.; Lubitz, W.; Happe, T. Importance of the Protein Framework for Catalytic Activity of [FeFe]-Hydrogenases. $J$. Biol. Chem. 2012, 287 (2), 1489-1499. https://doi.org/10.1074/jbc.M111.305797.

(36) Lampret, O.; Adamska-Venkatesh, A.; Konegger, H.; Wittkamp, F.; Apfel, U.-P.; Reijerse, E. J.; Lubitz, W.; Rü, O.; Happe, T.; Winkler, M. Interplay between CN Ligands and the Secondary Coordination Sphere of the H-Cluster in [FeFe]Hydrogenases. J. Am. Chem. Soc. 2017, 139 (50), 18222-18230. https://doi.org/10.1021/jacs.7b08735.

(37) Pham, C. C.; Mulder, D. W.; Pelmenschikov, V.; King, P. W.; Ratzloff, M. W.; Wang, H.; Mishra, N.; Alp, E. E.; Zhao, J.; Hu, M. Y.; et al. Terminal Hydride Species in [FeFe]-Hydrogenases Are Vibrationally Coupled to the Active Site Environment. Angew. Chemie Int. Ed. 2018, 57 (33), 10605-10609. https://doi.org/10.1002/anie.201805144.

(38) Mirmohades, M.; Adamska-Venkatesh, A.; Sommer, C.; Reijerse, E.; Lomoth, R.; Lubitz, W.; Hammarström, L. Following [FeFe] Hydrogenase Active Site Intermediates by Time- Resolved Mid-IR Spectroscopy. J. Phys. Chem. Lett. 2016, 7, 3290-3293. https://doi.org/10.1021/acs.jpclett.6b01316.

(39) Schultz, B.-J.; Mohrmann, H.; Lorenz-Fonfria, V. A.; Heberle, J. Protein Dynamics Observed by Tunable Mid-IR Quantum Cascade Lasers across the Time Range from 10 Ns to 1 S. Spectrochim. Acta - Part A Mol. Biomol. Spectrosc. 2017, 188, 666 - 674. https://doi.org/10.1016/j.saa.2017.01.010.

(40) Fourmond, V.; Greco, C.; Sybirna, K.; Baffert, C.; Wang, P.-H.; Ezanno, P.; Montefiori, M.; Bruschi, M.; Meynial-Salles, I.; Soucaille, P.; et al. The Oxidative Inactivation of FeFe Hydrogenase Reveals the Flexibility of the H-Cluster. Nat. Chem. 2014, 6 (4), 336-342. https://doi.org/10.1038/nchem.1892.

(41) Goldet, G.; Brandmayr, C.; Stripp, S. T.; Happe, T.; Cavazza, C.; Fontecilla-Camps, J. C.; Armstrong, F. A. Electrochemical Kinetic Investigations of the Reactions of [FeFe]-Hydrogenases with Carbon Monoxide and Oxygen: Comparing the Importance of Gas Tunnels and Active-Site Electronic/Redox Effects. J. Am. Chem. Soc. 2009, 131 (41), 14979-14989. https://doi.org/10.1021/ja905388j.

(42) Camara, J. M.; Rauchfuss, T. B. Combining Acid-base, Redox and Substrate Binding Functionalities to Give a Complete Model for the [FeFe]-Hydrogenase. Nat. Chem. 2012, 4 (1), 26-30. https://doi.org/10.1038/nchem.1180.

(43) Schilter, D.; Camara, J. M.; Huynh, M. T.; Hammes-Schiffer, S.; Rauchfuss, T. B. Hydrogenase Enzymes and Their Synthetic Models: The Role of Metal Hydrides. Chem. Rev. 2016, 116 (15), 8693-8749. https://doi.org/10.1021/acs.chemrev.6b00180.

(44) Möller, F.; Piontek, S.; Miller, R. G.; Apfel, U.-P. From Enzymes To Functional Materials - Towards Activation Of Small Molecules. Chem. - A Eur. J. 2017, 24 (7), 1471-1493. https://doi.org/10.1002/chem.201703451.

(45) Mebs, S.; Kositzki, R.; Duan, J.; Kertess, L.; Senger, M.; Wittkamp, F.; Apfel, U.-P.; Happe, T.; Stripp, S. T.; Winkler, M.; et al. Hydrogen and Oxygen Trapping at the H- 
Cluster of [FeFe]-Hydrogenase Revealed by Site-Selective Spectroscopy and QM/MM Calculations. Biochim. Biophys. Acta - Bioenerg. 2018, 1859 (1), 28-41.

https://doi.org/10.1016/j.bbabio.2017.09.003.

(46) Stripp, S. T.; Happe, T. How Algae Produce Hydrogen - News from the Photosynthetic Hydrogenase. Dalt. Trans. 2009, 45, 9960-9969. https://doi.org/10.1039/b916246a.

(47) Ghirardi, M. L.; Posewitz, M. C.; Maness, P.-C.; Dubini, A.; Yu, J.; Seibert, M. Hydrogenases and Hydrogen Photoproduction in Oxygenic Photosynthetic Organisms. Annu. Rev. Plant Biol. 2007, 58 (1), 71-91. https://doi.org/10.1146/annurev.arplant.58.032806.103848.

(48) Swanson, K. D.; Ratzlo, M. W.; Mulder, D. W.; Artz, J. H.; Ghose, S.; Ho, A.; White, S.; Zadvornyy, O. A.; Broderick, J. B.; Bothner, B.; et al. [FeFe]-Hydrogenase Oxygen Inactivation Is Initiated at the H Cluster 2Fe Subcluster. J. Am. Chem. Soc. 2015, 137 (5), 1809-1816. https://doi.org/10.1021/ja510169s.

(49) Albracht, S. P. J.; Roseboom, W.; Hatchikian, E. C. The Active Site of the [FeFe]Hydrogenase from Desulfovibrio Desulfuricans. I. Light Sensitivity and Magnetic Hyperfine Interactions as Observed by Electron Paramagnetic Resonance. J. Biol. Inorg. Chem. 2006, 11 (1), 88-101. https://doi.org/10.1007/s00775-005-0039-8.

(50) Mebs, S.; Duan, J.; Wittkamp, F.; Stripp, S. T.; Happe, T.; Apfel, U. P.; Winkler, M.; Haumann, M. Differential Protonation at the Catalytic Six-Iron Cofactor of [FeFe]Hydrogenases Revealed by 57 Fe Nuclear Resonance X-Ray Scattering and Quantum Mechanics/Molecular Mechanics Analyses. Inorg. Chem. 2019, 58, 4000-4013. https://doi.org/10.1021/acs.inorgchem.9b00100. 


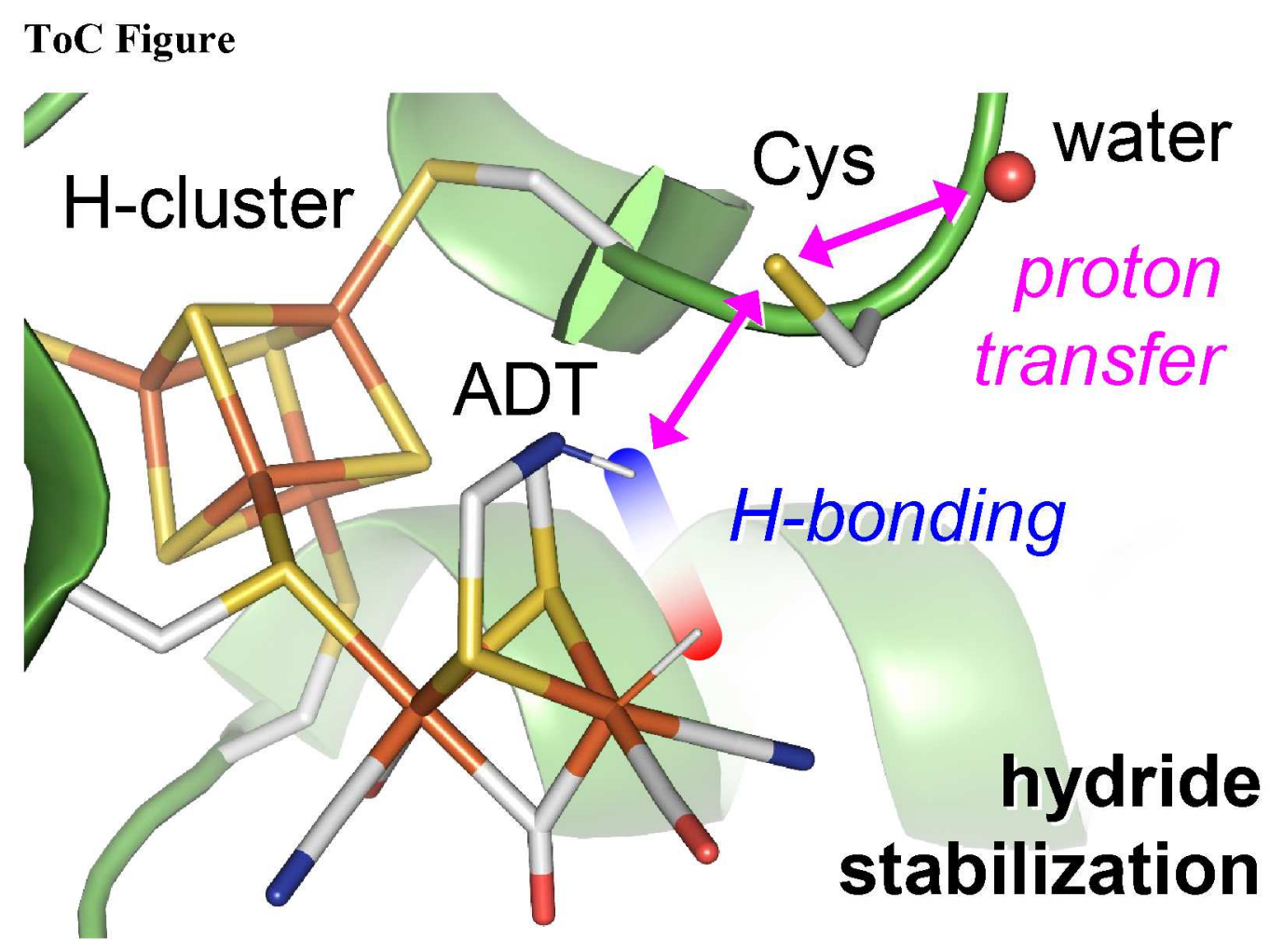

The geometry of the catalytic active site in [FeFe]-hydrogenases is determined by hydrogen bonding and proton transfer. 